\title{
High-Resolution Fibre Bragg Grating (FBG) Pressure Transducer for Low-Pressure Detection
}

\author{
Z. M. Hafizi ${ }^{1}$, E. Vorathin ${ }^{1}$, A. M. Aizzuddin ${ }^{1}$, and K. S. Lim ${ }^{2}$ \\ ${ }^{1}$ Advanced Structural Integrity and Vibration Research (ASIVR), \\ Faculty of Mechanical Engineering, Universiti Malaysia Pahang, 26600 Pekan, Pahang, \\ Malaysia \\ ${ }^{2}$ Photonics Research Centre, Faculty of Science, University of Malaya, \\ 50603 Kuala Lumpur,Malaysia \\ *Email: hafizi@ump.edu.my
}

\begin{abstract}
Fibre Bragg grating (FBG) pressure sensor has shown great potential in replacing the conventional electrical pressure sensor due to its adaptability to the harsh environment. However, increasing its resolution for low-pressure measurement is still a challenge. In this work, the bonding of FBG to a rubber-based diaphragm pressure transducer was proposed. The proposed pressure transducer had enhanced the sensitivity to $117.7 \mathrm{pm} / \mathrm{kPa}$ across the range of $40 \mathrm{kPa}$, which corresponded to the pressure resolution of $0.008 \mathrm{kPa}$. Furthermore, the proposed pressure transducer possessed a reference FBG for temperature compensation, where the overall temperature effect was less than $1 \%$.
\end{abstract}

Keywords: Fibre Bragg grating (FBG); pressure sensor; temperature compensation.

\section{INTRODUCTION}

Pressure sensing has always been a primary concern in most engineering demands, such as oil and gas, hydraulic and pneumatic, petrochemical, and aerospace [1]. These heavy and harsh industries are putting traditional electrical pressure sensors at risk, where they are vulnerable to an explosion caused by sparks from a severe change in temperature and pressure, and intense electromagnetic interference (EMI) due to long transmission lines [2-4]. To overcome this deficiency, Fibre Bragg grating (FBG) sensors have been vastly utilised due to their capability to adapt the harsh environment with resistance to the explosion, lightweight, small physical size and immunity to EMI [5-7]. Xu et al. [8] reported on the first bare FBG pressure sensor with a recorded pressure sensitivity at $3.04 \times 10^{-3} \mathrm{pm} / \mathrm{kPa}$. However, such sensitivity was too low for low-pressure detection. Pressure measurement can be categorised into three ranges, which are low pressure $(\leq$ $10 \mathrm{kPa}$ ), medium pressure $(>10 \mathrm{kPa}$ ) and high pressure ( $\geq 1 \mathrm{MPa})$ [9]. Low-pressure measurement in the range of below $10 \mathrm{kPa}$ is the most challenging as it requires higher resolution for better accuracy as compared to medium and high-pressure measurements $[10,11]$. By interrogating the sensitivity of a bare FBG with a standard 1-pm interrogator [12-16], the pressure resolution was retrieved at $329 \mathrm{kPa}$, which was unable to detect the low-pressure measurement.

Concurrently, a bare FBG is also sensitive to temperature variations with sensitivity at $0.01045 \mathrm{~nm} /{ }^{\circ} \mathrm{C}$ [8]. This temperature sensitivity will also affect the accuracy of pressure measurement, which truly requires a temperature compensation technique. Therefore, a robust FBG pressure transducer for low-pressure detection should possess 
high resolution and is insensitive to temperature effects. Regarding this, various encapsulation methods with diverse temperature compensation techniques were reported. Polymer filled structure [17-20], cantilever beam structure [13, 21], metal bellows structure $[1,22,23]$ and diaphragm-based structure [10, 16, 24-26] appeared to be favourable to most researchers. Pachava et al. [1] bonded two FBGs to a metal bellow, where one of the FBGs is to sense the pressure strain while the other is to compensate the temperature variations. As a result, the sensitivity of temperature insensitive pressure was recorded at $13.14 \mathrm{pm} / \mathrm{kPa}$, which corresponded to $0.076 \mathrm{kPa}$ of pressure resolution in relative to 1-pm of wavelength shifts. Two FBGs that underwent redshift and blueshift developed by Liang et al. [13] have retrieved a resolution at $2.941 \mathrm{kPa}$ with a recorded sensitivity of $0.34 \mathrm{pm} / \mathrm{kPa}$. However, such structures were complicated with a complex packaging method.

Zheng et al. [19] utilised a single FBG by encapsulating half of the grating in a polymer-filled cylinder while the other half in a metal cylinder. This resulted in different sensitivities that split the single reflected wavelength into two to compensate the variations in temperature. The polymer-filled structure was capable of increasing the resolution to $0.067 \mathrm{kPa}$ with the sensitivity at $14.92 \mathrm{pm} / \mathrm{kPa}$ [19]. However, two host materials with different thermal expansions were needed, which could add up to the cost of a direct pressure transducer. A simple structure such as the diaphragm-based seems to be capable of enhancing the pressure resolution of the FBG sensor. Pachava et al. [10] bonded an FBG on a thin metal diaphragm and obtained a sensitivity at $32.02 \mathrm{pm} / \mathrm{kPa}$, which gave a pressure resolution of $0.031 \mathrm{kPa}$. However, most of the pressure above transducer had reported on a pressure resolution in the order of $10^{-2} \mathrm{kPa}$.

Overall, a high-resolution pressure transducer can only be achieved with a highpressure sensitivity. Therefore, this study reported on a high-resolution pressure transducer by bonding an FBG to a rubber-based diaphragm pressure transducer to enhance the sensitivity. Rubber has a very low Young's modulus value as compared to other materials, such as a metallic diaphragm [10, 16, 24-26]. Since FBG works on the strain elongation principle, the bonding of FBG to a low Young's modulus material will result in a large elongation that is capable of enhancing the sensitivity. For temperature compensation, a built-in reference FBG bonded on the same structure was utilised to sense the temperature effects. As a result, the proposed pressure transducer retrieved a pressure resolution of $0.008 \mathrm{kPa}$, which was in the order of $10^{-3} \mathrm{kPa}$. Moreover, the total temperature effect was less than $1 \%$ of the overall sensing range.

\section{DESIGN AND MODELLING}

The method for fabricating the proposed FBG pressure transducer is very simple. It mainly consists of a retaining ring, rubber diaphragm, pressure chamber, rubber ring, and air hose fitting, as shown in Figure 1 (a) and Figure 1 (b). The pressure chamber is a hollow cylindrical part with thickness and an inner diameter of $20 \mathrm{~mm}$ and $45 \mathrm{~mm}$, respectively. The total length of the pressure chamber is $40 \mathrm{~mm}$. A rubber ring with the same thickness as the rubber diaphragm is attached on top of the pressure chamber for equal thermal experience between the sensing and reference FBGs. The bottom part of the pressure chamber is fastened with an air hose fitting. Both FBGs used to have uniform grating with a length of $10 \mathrm{~mm}$. Germanosilica doped single mode fibre (SMF-28), with a core diameter of $\sim 9-10 \mu \mathrm{m}$, was used for the grating inscription. Prior to the inscription process, the fibre was photosensitised in a high-pressure hydrogen chamber at 2000 PSI for a week. All inscription processes were carried out by using $248 \mathrm{~nm} \mathrm{KrF}$ excimer laser 
and phase mask. Pressure inlet from the fitting will accumulate inside the chamber and deform the rubber membrane attached to the other side of the cylinder. Assuming that the pressure distribution is uniform across the entire diaphragm, and provided that the edge of the diaphragm is fixed to the cylinder, strain experienced by the diaphragm can be modelled by using a deformation theory. The deformation theory can be derived into radial, tangential, and centre strains, as shown in Figure 2 [24, 26].

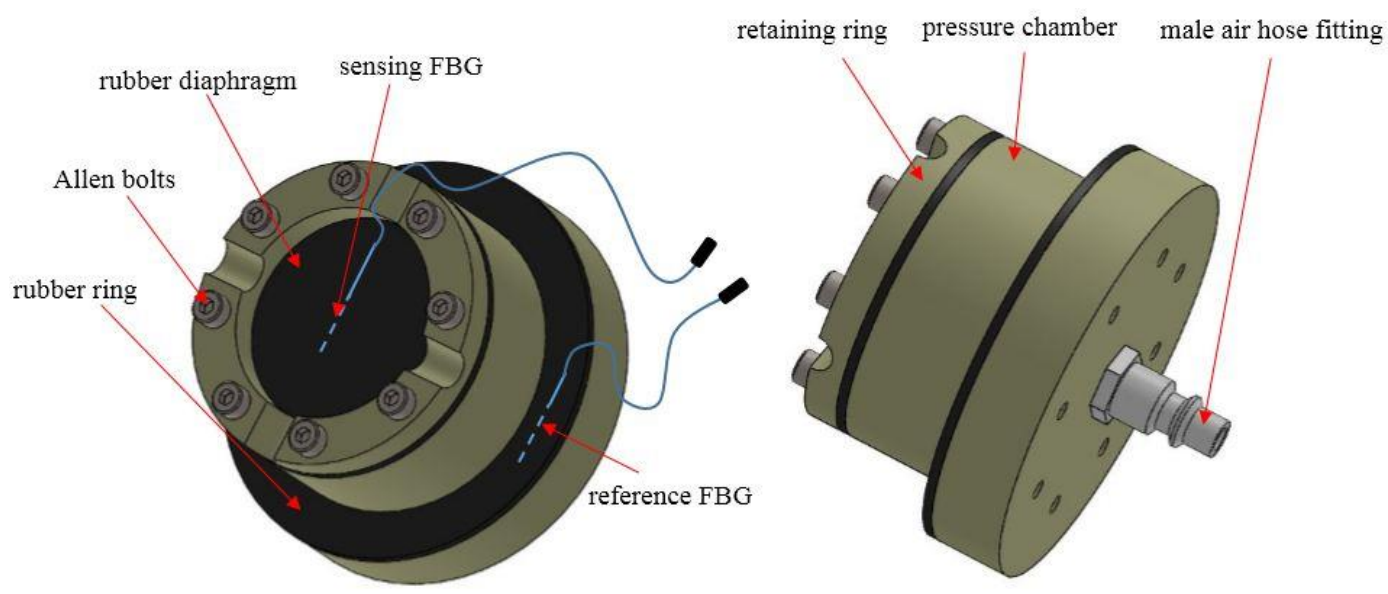

(a)
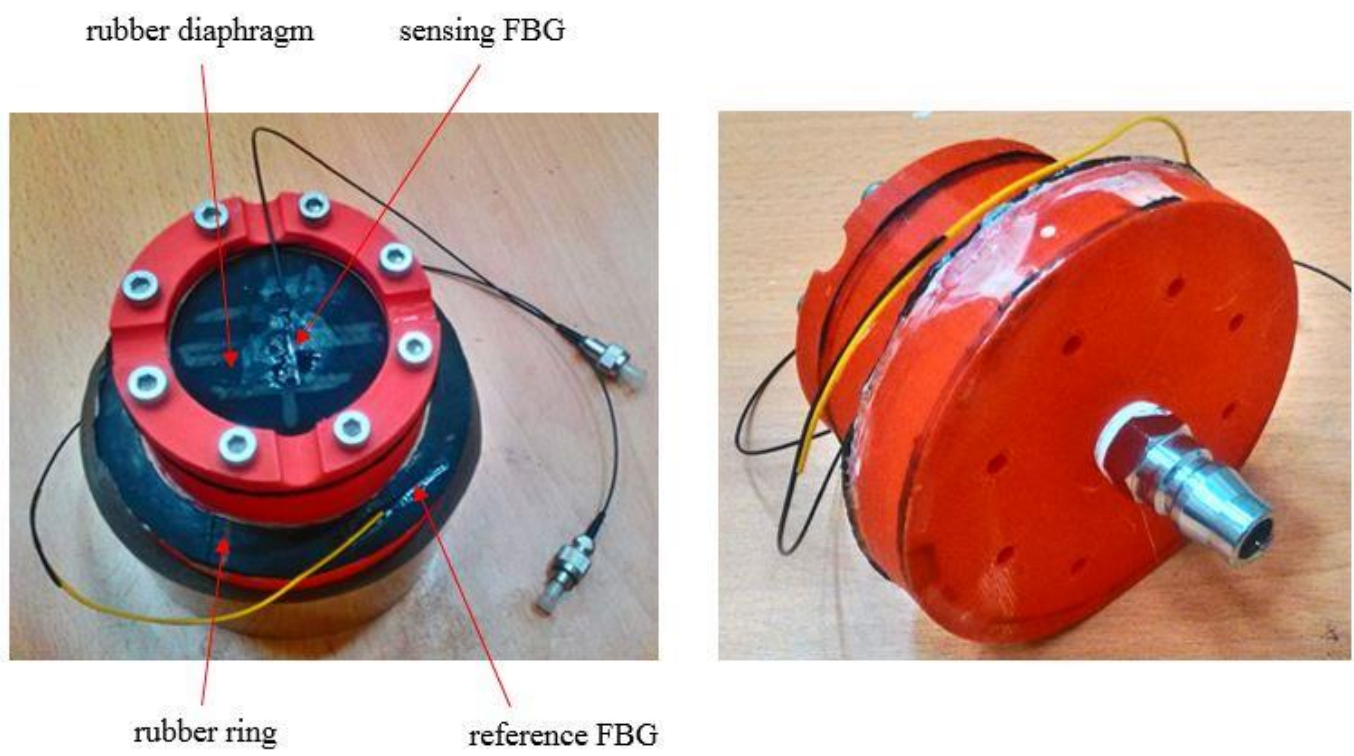

(b)

Figure 1. The proposed pressure transducer (a) schematic design and; (b) picture.

The radial strain, $\varepsilon_{r}$, tangential strain, $\varepsilon_{t}$ and centre strain, $\varepsilon_{c}$ as a function of applied pressure, $P$, can be expressed as $[24,26]$ :

$\varepsilon_{r}=\frac{3\left(1-v^{2}\right)\left(R^{2}-3 r^{2}\right)}{8 E_{r} h^{2}} P$ 
$\varepsilon_{t}=\frac{3\left(1-v^{2}\right)\left(R^{2}-r^{2}\right)}{8 E_{r} h^{2}} P$

$\varepsilon_{c}=\frac{3 \sqrt{2}\left(1-v^{2}\right) R^{2}}{8 E_{r} h^{2}} P$

Where $E_{r}$ is Young's modulus of rubber at $2.4 \mathrm{MPa}$ and $v$ is the Poisson ratio at 0.49 . The thickness and radius of the diaphragm, denoted by $h$ and $R$, are $1.26 \mathrm{~mm}$ and 22.5 $\mathrm{mm}$, respectively. $r$ is the displacement from a point of measurement to the centre of the diaphragm.

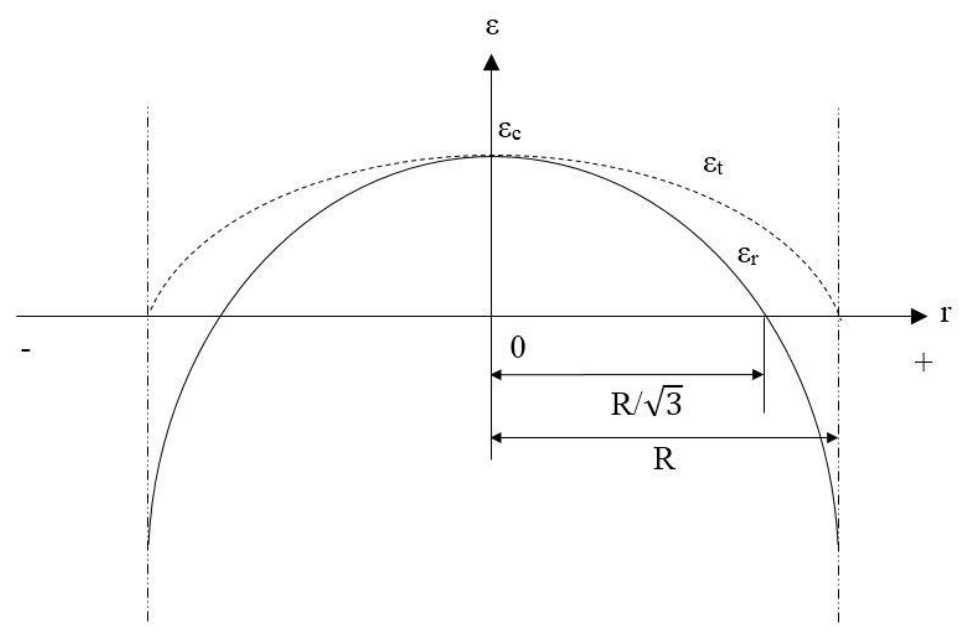

Figure 2. The strain distribution curve for the circular diaphragm $[24,26]$.

Figure 3 shows the MATLAB modelling of the radial, tangential and centre strains distribution curves for the rubber diaphragm. Figure 3 (a) and Figure 3 (b) show the relation of radial and tangential strain values when $P$ varies from $0 \mathrm{kPa}$ to $40 \mathrm{kPa}$ with an increment of $1 \mathrm{kPa}$, and $r$ varies from $-22.5 \mathrm{~mm}$ to $22.5 \mathrm{~mm}$ with an increment of 0.1 $\mathrm{mm}$. Figure 3 (c) shows the calculated centre strain when the radius varies from $0 \mathrm{~mm}$ up to the available size of $22.5 \mathrm{~mm}$, while the thickness varies from $0 \mathrm{~mm}$ up to the available thickness of $1.26 \mathrm{~mm}$. 


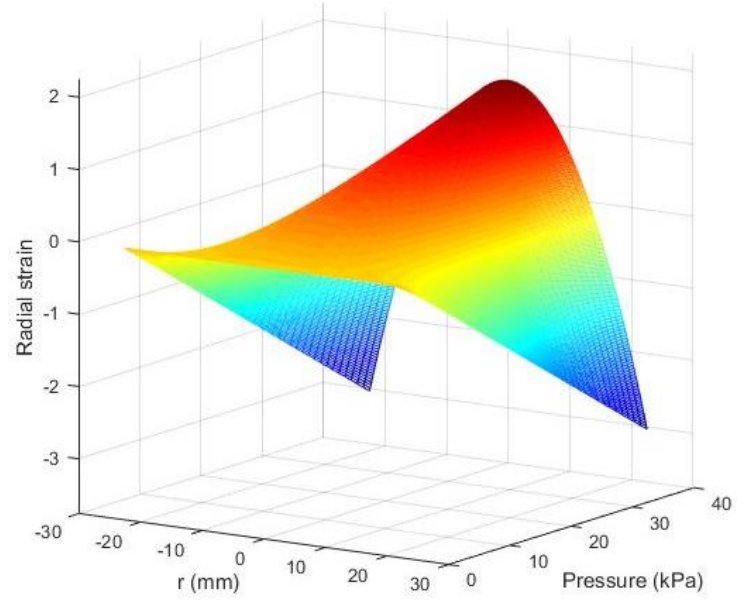

(a)

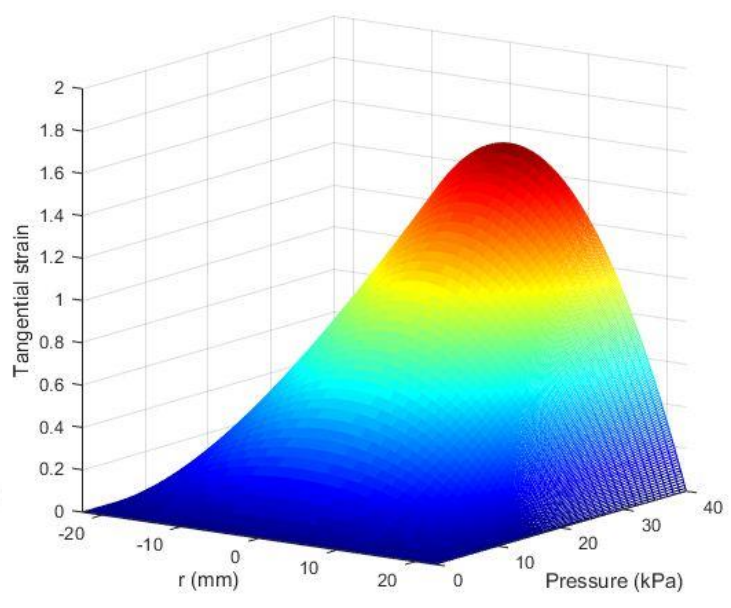

(b)

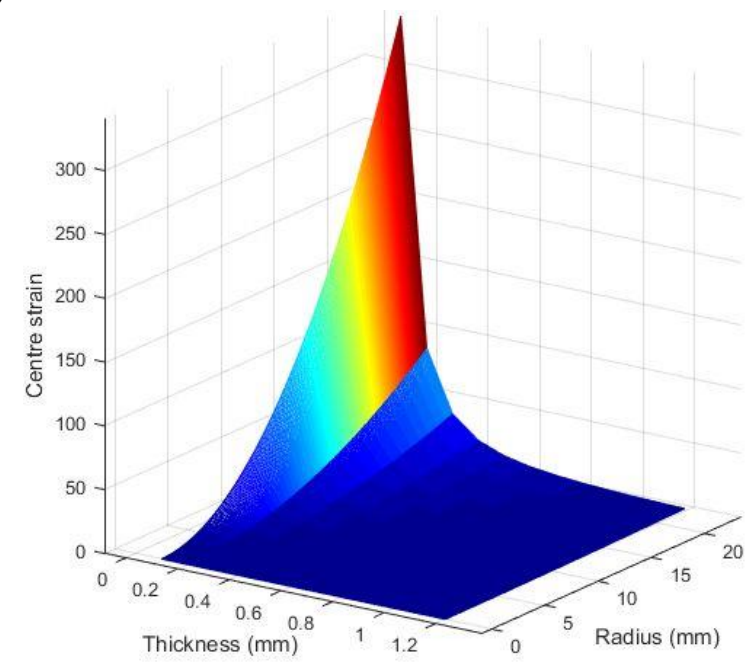

(c)

Figure 3. The (a) radial (b) tangential (c) centre strain distribution curves.

From the results, it was clear that the largest radial and tangential strains were achieved at the maximum displacement and pressure. The large strain was achieved due to the low modulus of elasticity of rubber as compared to the optical fibre, which limited the strain deformation of rubber. From Eq. (3), it was certain that the centre strain was influenced by the thickness and radius of the rubber diaphragm. The centre strain increased proportionally with increasing radius and decreased with greater thickness. Therefore, at a constant thickness, a greater radius was required to increase the strain of the diaphragm.

Since the sensing FBG (SFBG), with a wavelength of $1547.238 \mathrm{~nm}$, was bonded on the diaphragm, it was predicted that the change of relative Bragg wavelength was sensitive to both the pressure and temperature measurements which can be expressed as $[16,20]$ :

$$
\frac{\Delta \lambda_{S F B G}}{\lambda_{S F B G}}=\left(1-p_{e}\right) \varepsilon_{f}+\left(\hat{a}_{f}+\xi_{f}\right) \Delta \mathrm{T}
$$


Where, $p_{e}$ is the photoelastic constant at $0.22, \hat{\mathbf{a}}_{f}$ and $\xi_{f}$ is the fibre thermal expansion and thermo-optic coefficient at $0.55 \times 10^{-6}{ }^{\circ} \mathrm{C}^{-1}$ and $6.8 \times 10^{-6}{ }^{\circ} \mathrm{C}^{-1}$. Strain acting on the fibre is denoted by $\varepsilon_{f}$ while $\Delta \mathrm{T}$ is the temperature change. The strain from the optical fibre that limits the deformation of the diaphragm can be expressed as [27]:

$\varepsilon_{f}=\varepsilon_{c} \frac{E_{r} \cdot d_{r}}{E_{f} \cdot d_{f}}$

Where, $d_{r}$ is the diameter of the diaphragm. The Young's modulus and a total diameter of the fibre are denoted with $E_{f}$ and $d_{f}$, which are obtained at $70 \mathrm{GPa}$ and $125 \mu \mathrm{m}$. Therefore, by rearranging Eq. (3) to Eq. (5), the total relative Bragg wavelength change of the SFBG in terms of pressure and temperature effects can be rewritten as:

$$
\frac{\Delta \lambda_{S F B G}}{\lambda_{S F B G}}=\frac{3 \sqrt{2}\left(1-p_{e}\right)\left(1-v^{2}\right) R^{2} E_{r} d_{r}}{8 E_{r} E_{f} h^{2} d_{f}} P+\left[\xi_{f}+\left(1-p_{e}\right) \hat{\mathrm{a}}_{r}\right] \Delta \mathrm{T}
$$

The reference FBG (RFBG), with the wavelength of $1543.818 \mathrm{~nm}$, was bonded on top of the pressure chamber and expected to be free from any pressurised strain and sensitive to only the thermal expansion of the rubber, $\hat{a}_{r}$ which can be expressed as:

$$
\frac{\Delta \lambda_{R F B G}}{\lambda_{R F B G}}=\left[\xi_{f}+\left(1-p_{e}\right) \hat{\mathrm{a}}_{r}\right] \Delta \mathrm{T}
$$

In order to compensate the temperature effects, both FBGs must possess the same temperature sensitivity, which can be expressed as:

$$
K_{T}=\left[\lambda_{\text {avg }}\left(\xi_{f}+\left(1-p_{e}\right) \hat{a}_{r}\right)\right]
$$

Utilising the average wavelength, $\lambda_{\text {avg }}$ as $1545 \mathrm{~nm}$ and $\hat{\mathrm{a}}_{r}$ as $80 \times 10^{-6}{ }^{\circ} \mathrm{C}^{-1}$, the temperature sensitivity, $K_{T}$ can be obtained at $0.1069 \mathrm{~nm} /{ }^{\circ} \mathrm{C}$. By deducting away Eq. (7) from Eq. (6), the temperature insensitive Bragg wavelength change can be expressed as:

$$
\begin{aligned}
& \Delta \lambda_{S F B G}-\Delta \lambda_{R F B G}=K_{P} P \\
& \text { where } K_{P}=\frac{3 \sqrt{2} \lambda_{\text {avg }}\left(1-p_{e}\right)\left(1-v^{2}\right) R^{2} E_{r} d_{r}}{8 E_{r} E_{f} h^{2} d_{f}}
\end{aligned}
$$

Where, the pressure sensitivity, $K_{p}$ can be obtained at $796.45 \mathrm{pm} / \mathrm{kPa}$. From Eq. (9), it was seen that FBG used the reflected wavelength to detect the change of strain, which depended on the use of specific wavelength. According to a study by Fu et al. [28], a lower wavelength at $1320 \mathrm{~nm}$ had a slightly higher sensitivity of about $23 \%$ higher than $1550 \mathrm{~nm}$ wavelength FBG. 


\section{EXPERIMENTAL SETUP}

The performance of the proposed FBG pressure transducer towards pressure and temperature effects were evaluated by first carrying out the pressure measurement at a constant laboratory temperature of $27.5^{\circ} \mathrm{C}$. Next, the temperature was investigated at a constant pressure measurement of $0 \mathrm{kPa}$. All Bragg wavelength shifts were recorded, analysed and compared to other reported works.

By attaching the pressure transducer to an air storage tank, the pressure was varied from $0 \mathrm{kPa}$ to $40 \mathrm{kPa}$ with a step of $5 \mathrm{kPa}$. Both FBGs were illuminated by a broadband Amplified Spontaneous Emission (ASE) light source through a 2x2 optical coupler, as shown in Figure 4. The reflected wavelengths were observed from the optical spectrum analyser (OSA) with a resolution of 2-pm.

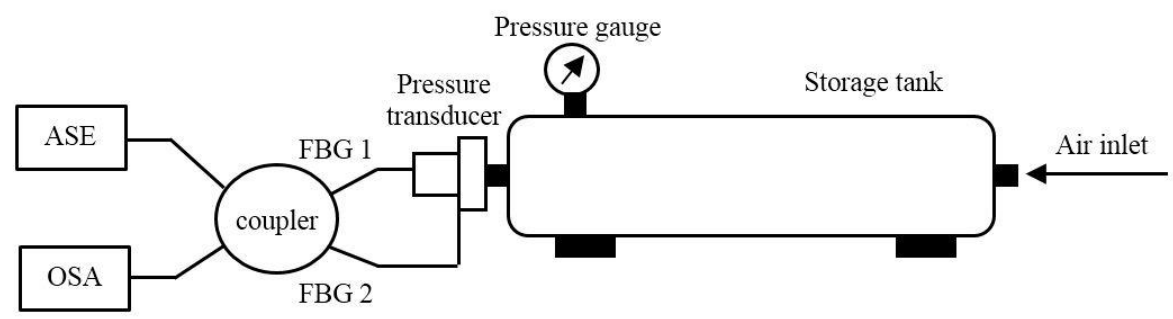

Figure 4. The experimental setup.

\section{RESULTS AND DISCUSSION}

\section{Pressure}

Figure 5 shows the reflected SFBG and RFBG spectrum at certain applied pressure. From the result, it was seen that the SFBG spectrum shifted to a higher wavelength with increasing pressure, while the wavelength of RFBG remained constant throughout the pressure variations. Also, all spectra did not have any significant change in shape.

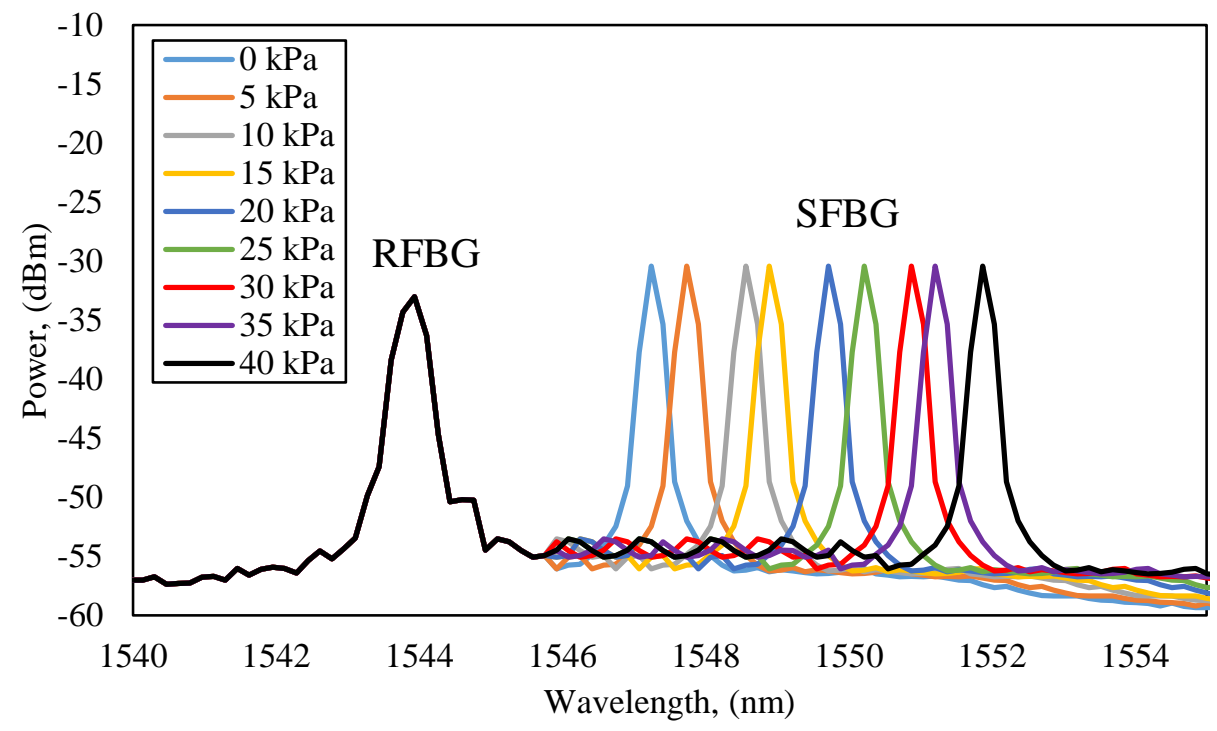

Figure 5. The reflected spectra of SFBG and RFBG at certain applied pressure. 
Figure 6 (a) shows the centre wavelength shifts of both FBGs when the pressure was varied from $0 \mathrm{kPa}$ to $40 \mathrm{kPa}$ with a step of $5 \mathrm{kPa}$. The pressure transducer was experimented with multiple increasing and decreasing in pressure to evaluate the repeatability performance. From the result, it was observed that the centre wavelength of SFBG was shifted towards a higher wavelength linearly against the increasing pressure. Initially, the average centre wavelength of SFBG was recorded at $1547.237 \mathrm{~nm}$ had shifted to a final wavelength of $1551.953 \mathrm{~nm}$ at the maximum pressure of $40 \mathrm{kPa}$. However, the wavelength of RFBG remained static without any slight shifting at $1543.818 \mathrm{~nm}$; thus, certifying that it was free from any pressurised strain. Figure 6 (b) shows the standard deviation of SFBG against the applied pressure. The highest standard deviation was recorded at only $0.046 \mathrm{~nm}$. This small standard deviation justified that the proposed pressure transducer has consistency and reliability in performing multiple testing.

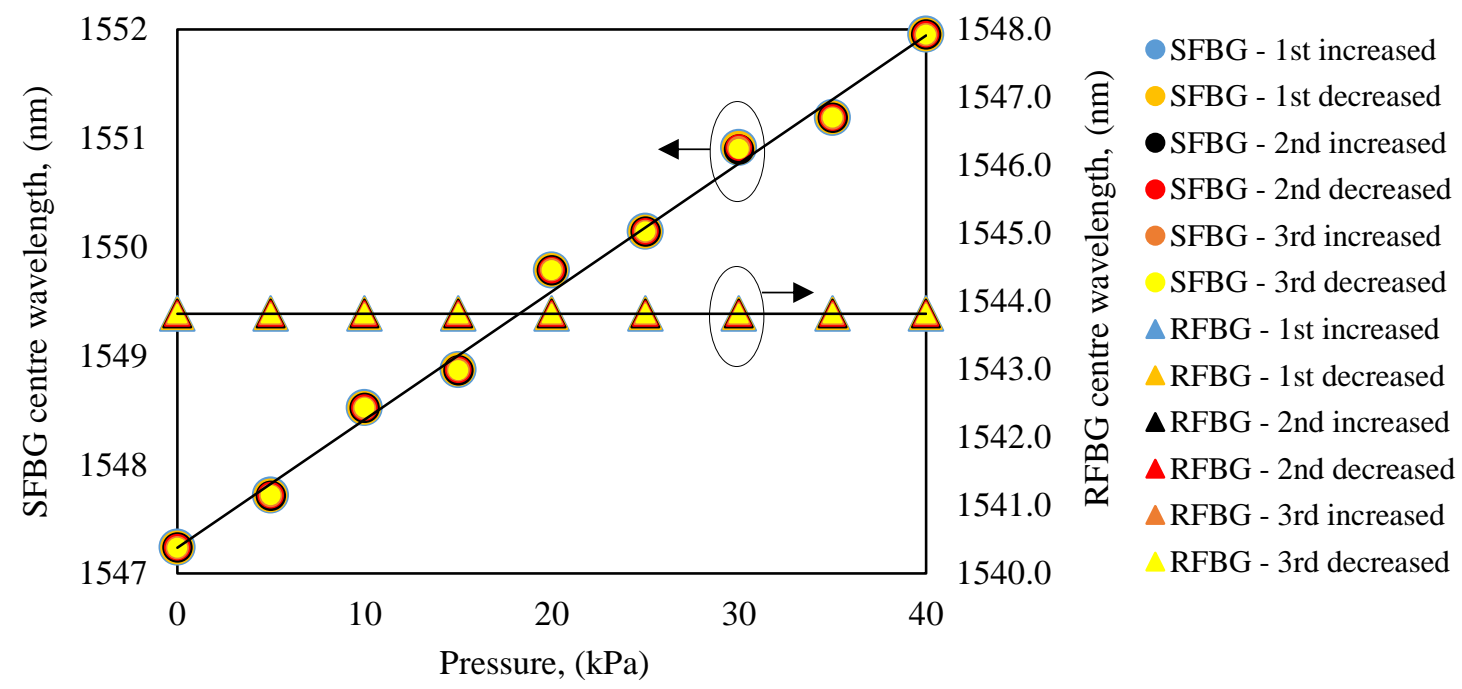

(a)

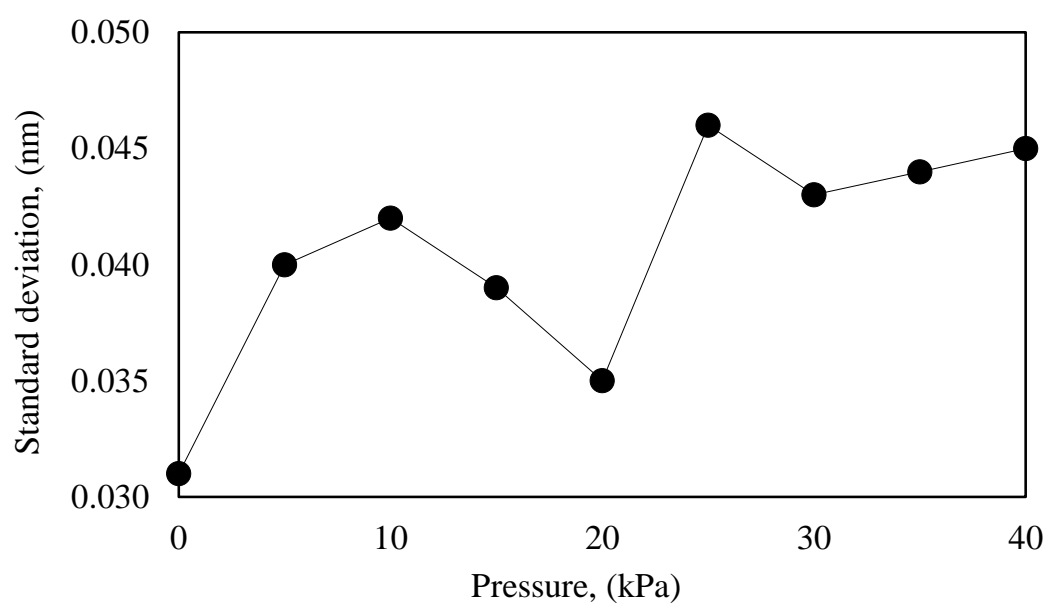

(b)

Figure 6. The repeatability test of the pressure transducer (a) centre wavelength of SFBG and RFBG and (b) standard deviation of SFBG. 
By averaging the response curve, as shown in Figure 7, the pressure sensitivity of the sensor across $40 \mathrm{kPa}$ was recorded at $117.7 \mathrm{pm} / \mathrm{kPa}$. The experimentally obtained pressure sensitivity was much lower than the predicted sensitivity, which was mainly due to the harden massive glue used during the FBG bonding that reduced the strain deformation of the diaphragm $[29,30]$.

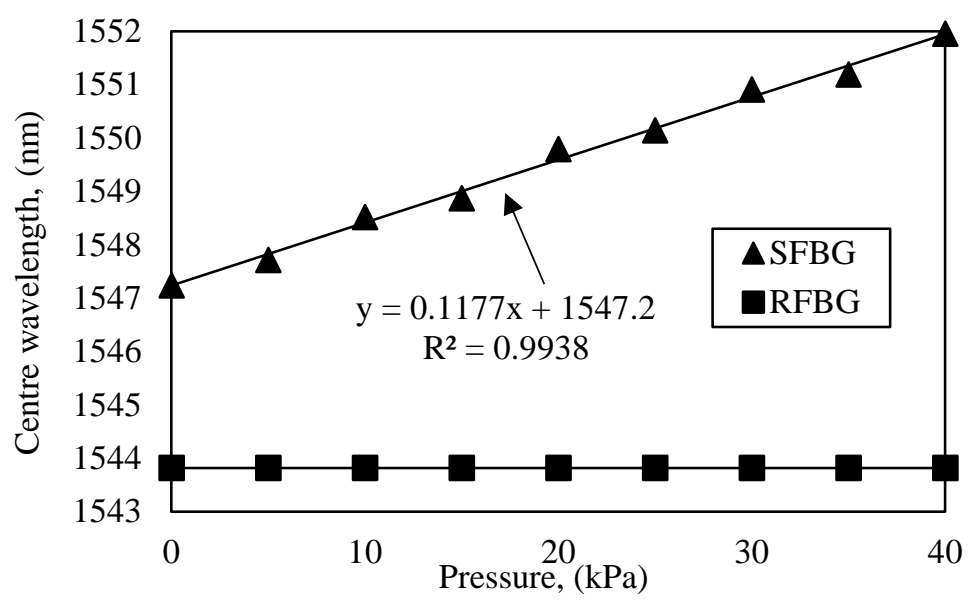

Figure 7. The average linear fit of the response curve versus pressure.

The experimentally obtained pressure sensitivity at $117.7 \mathrm{pm} / \mathrm{kPa}$ retrieved a pressure resolution of $0.008 \mathrm{kPa}$ relative to $1-\mathrm{pm}$ of wavelength resolution. The pressure resolution, which was the minimum detectable pressure at $0.008 \mathrm{kPa}$ depended on the wavelength resolution of the OSA, performance of the FBG sensor and surrounding noise. However, the design of the structure did not affect the measurement resolution. The high resolution proposed pressure transducer will give higher accuracy when utilised for lowpressure applications, such as the heating, ventilation and air conditioning (HVAC) system. Furthermore, the diaphragm was capable of withstanding an induced pressure of up to $40 \mathrm{kPa}$ without any damage. The maximum measurable pressure was limited to only $40 \mathrm{kPa}$ as pressure beyond this range will damage the FBG sensor. Therefore, the use of rubber material can provide high sensitivity for low-pressure applications but with reduced measurable pressure range. Manipulation of the sensitivity and range can be further optimised from the choice of material, diameter and thickness of the diaphragm. The measurable range from $0.008 \mathrm{kPa}$ to $40 \mathrm{kPa}$ gave a dynamic range $(D R)$ at $74 \mathrm{~dB}$, which can be calculated as [31]:

$D R(d B)=20 \times \log _{10}\left(\frac{P_{\max }}{P_{\min }}\right)$

Where $P_{\max }$ is the maximum pressure and $P_{\min }$ is the minimum pressure. The obtained resolution was much higher than any of the reported works as summarised in Table 1. The sensitivity of the proposed pressure transducer was 38,717 times much higher than the bare FBG [8], three times much higher than the polymer half-filled metal cylinder [20], 346 times much higher than the cantilever structure [13] and more than twice much higher than the metal bellows structure [23]. 
Table 1. The comparison of sensitivity and resolution of the proposed pressure transducer with various up-to-date pressure transducers.

\begin{tabular}{ccccc}
\hline Structure & Material & Ref. & $\begin{array}{c}\text { Sensitivity, } \\
(\mathrm{pm} / \mathrm{kPa})\end{array}$ & $\begin{array}{c}\text { Resolution, } \\
(\mathrm{kPa})\end{array}$ \\
\hline polymer filled & polymer & {$[17]$} & 5.28 & 0.189 \\
& polymer & {$[32]$} & 8.7 & 0.115 \\
& polymer & {$[19]$} & 14.92 & 0.067 \\
& polymer & {$[20]$} & 33.876 & 0.03 \\
\hline cantilever beam & polyether-ether & {$[21]$} & 0.133 & 7.519 \\
& -ketone (PEEK) plastic & & & \\
& 304 stainless steel & {$[13]$} & 0.34 & 2.941 \\
\hline metal bellows & - & {$[22]$} & 11.96 & 0.084 \\
& 316L stainless steel & {$[1]$} & 13.14 & 0.076 \\
& aluminium & {$[23]$} & 48 & 0.021 \\
\hline diaphragm based & metal film & {$[25]$} & 0.024 & 41.667 \\
& 304 stainless steel & {$[24]$} & 1.57 & 0.637 \\
& - & {$[26]$} & 3.56 & 0.281 \\
& aluminium 6061 & {$[10]$} & 32.02 & 0.031 \\
\hline Proposed & rubber & & 117.7 & 0.008 \\
\hline
\end{tabular}

The Bragg wavelength shifted towards temperature effects was evaluated by submerging the pressure transducer in the water at a temperature of $30.7{ }^{\circ} \mathrm{C}$ and heated up to a maximum temperature of $55.7^{\circ} \mathrm{C}$ with an interval step of $5{ }^{\circ} \mathrm{C}$. Figure 8 shows the linear regression of both the FBGs response curves.

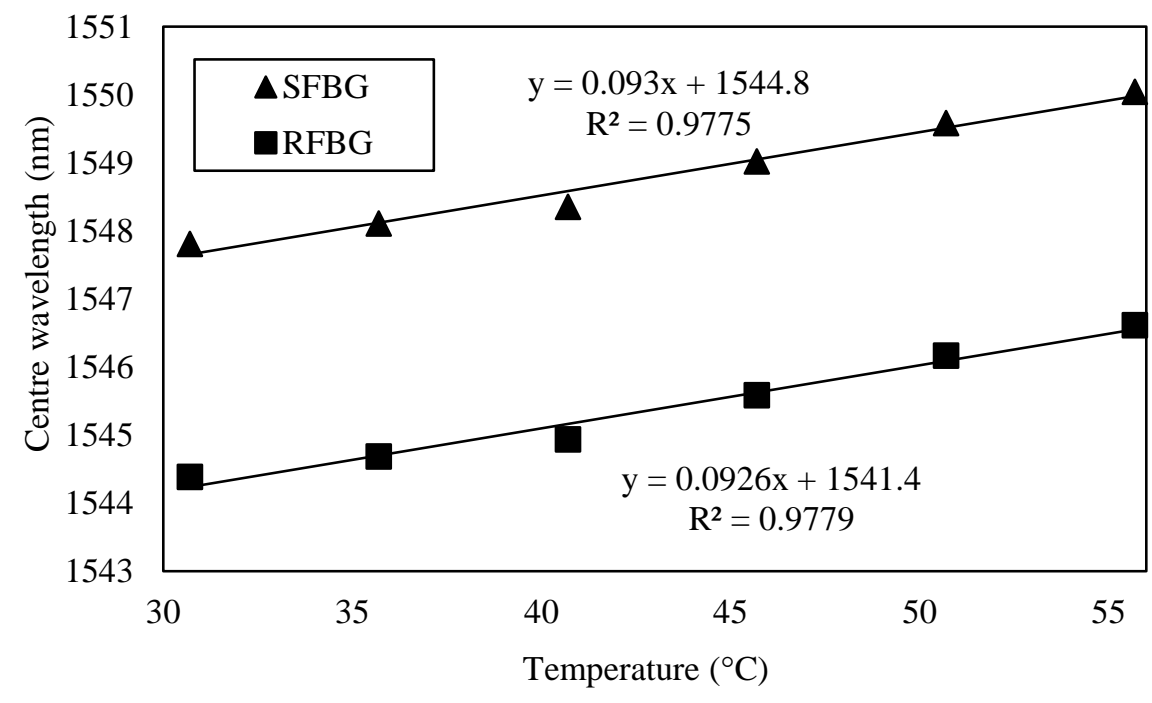

Figure 8. The linear regression of the response curve versus temperature.

The sensitivity of SFBG was recorded at $0.093 \mathrm{~nm} /{ }^{\circ} \mathrm{C}$ while $\mathrm{RFBG}$ was obtained at $0.0926 \mathrm{~nm} /{ }^{\circ} \mathrm{C}$. The experimentally obtained temperature sensitivity was in close agreement with the predicted temperature sensitivity. Since both FBGs possessed the same temperature sensitivity, the temperature effects can be compensated by subtracting away the wavelength of RFBG from SFBG, as shown in Figure 9. 


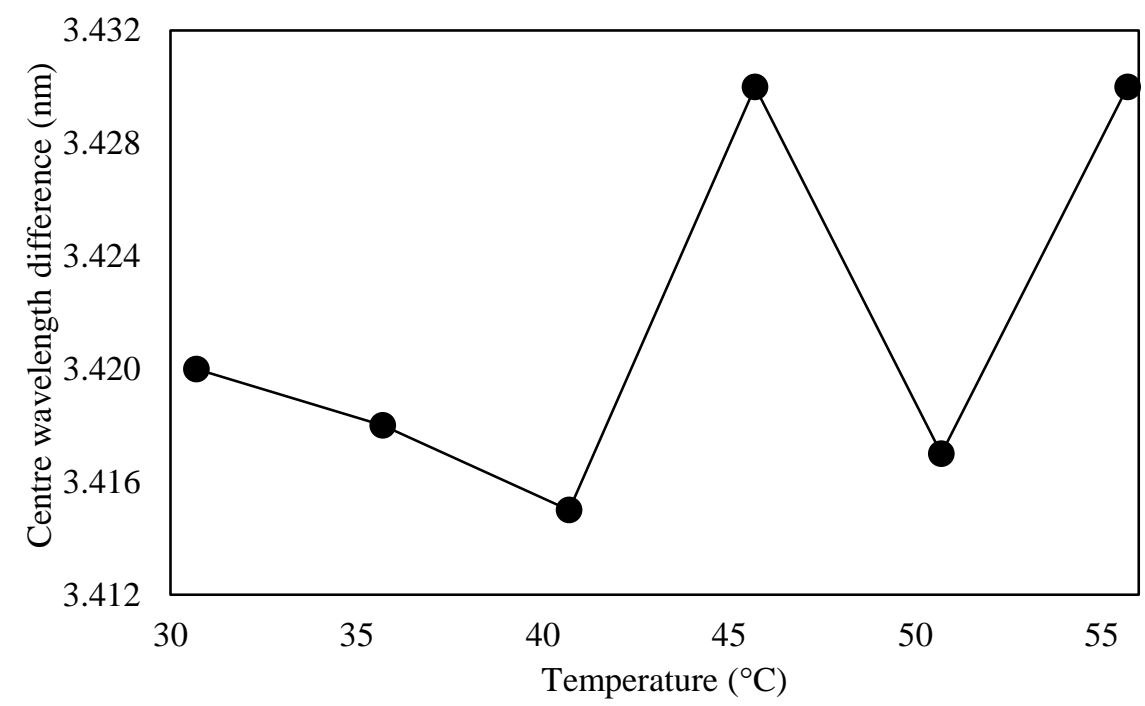

Figure 9. The centre wavelength difference between SFBG and RFBG versus temperature.

From the results, the highest centre wavelength difference between SFBG and RFBG was just $15 \mathrm{pm}$, which was equal to the pressure tolerance of $0.12 \mathrm{kPa}$ from the total sensitivity of $117.7 \mathrm{pm} / \mathrm{kPa}$. Across the total sensing range of $40 \mathrm{kPa}$, the temperature effect was just $0.3 \%$. This slight effect was negligible, making the proposed pressure transducer independence to temperature effects.

\section{CONCLUSION}

This paper has successfully presented a high-resolution FBG pressure transducer for lowpressure detection. The mechanism was based on the use of rubber diaphragm to enhance the sensitivity of the FBG. The experimental results showed that the pressure transducer had a sensitivity of $117.7 \mathrm{pm} / \mathrm{kPa}$, which corresponded to the pressure resolution 0.008 $\mathrm{kPa}$ across a sensing range of $40 \mathrm{kPa}$ with good linearity of $99.38 \%$. Furthermore, the proposed pressure transducer was insensitive to thermal strain due to the advancement of a built-in reference FBG.

\section{ACKNOWLEDGEMENT}

The authors would like to thank the Faculty of Mechanical Engineering, University Malaysia Pahang (http://www.ump.edu.my/) for providing the laboratory facilities and financial support. They would also like to thank the Photonics Research Centre University Malaya (PRCUM) for the support in fabricating the FBGs. Finally, special thanks to the Malaysian Ministry of Education for providing the FRGS phase 1/2016, with grant number RDU160136.

\section{REFERENCES}

[1] Pachava VR, Kamineni S, Madhuvarasu SS, Putha K, Mamidi VR. FBG based high sensitive pressure sensor and its low-cost interrogation system with enhanced resolution. Photonic Sensors 2015; 5(4): 321-329. 
[2] Ameen OF, Younus MH, Ibrahim RR, Rahman RA. Comparison of water level measurement performance for two different types of diaphragm using fiber bragg grating based optical sensors. Jurnal Teknologi 2016; 78(6-11): 97-101.

[3] Ameen OF, Younus MH, Aziz M, Ibrahim R. Temperature and water level measurement of liquid in a tank using fiber Bragg grating. Jurnal Teknologi 2016; 78(3): 261-265.

[4] Ameen OF, Younus MH, Abdul R. Water level measurement via polymer diaphragm and fiber bragg grating sensor. Jurnal Teknologi 2016; 78(3-2): 145148.

[5] Zhang YF, Hong CY, Ahmed R, Ahmed Z. A fiber Bragg grating based sensing platform fabricated by fused deposition modeling process for plantar pressure measurement. Measurement 2017; 112: 74-79.

[6] Feng WQ, Liu ZY, Tam HY, Yin JH. The pore water pressure sensor based on Sagnac interferometer with polarization-maintaining photonic crystal fiber for the geotechnical engineering. Measurement 2016; 90: 208-214.

[7] Zhang Z, Shen C, Li L. Temperature-independent fiber-Bragg-grating-based atmospheric pressure sensor. Optics Communications 2018; 411: 108-113.

[8] Xu M, Reekie L, Chow Y, Dakin JP. Optical in-fibre grating high pressure sensor. Electronics Letters 1993; 29(4): 398-399.

[9] Sindhanaiselvi D. Design and analysis of low pressure MEMS sensor. Doctoral dissertation. Pondicherry University; 2015.

[10] Pachava VR, Kamineni S, Madhuvarasu SS, Putha K. A high sensitive FBG pressure sensor using thin metal diaphragm. Journal of Optics 2014; 43(2): 117121.

[11] Song D, Wei Z, Zou J, Yang S, Du E, Cui HL. Pressure sensor based on fiber Bragg grating and carbon fiber ribbon-wound composite cylindrical shell. IEEE Sensors Journal 2009; 9(7): 828-831.

[12] Liang MF, Fang XQ, Ning YS. Temperature compensation fiber Bragg grating pressure sensor based on plane diaphragm. Photonic Sensors 2018; 8(2): 157-167.

[13] Liang MF, Fang XQ, Wu G, Xue GZ, Li HW. A fiber Bragg grating pressure sensor with temperature compensation based on diaphragm-cantilever structure. Optik 2017; 145: 503-512.

[14] Huang J, Zhou Z, Zhang D, Wei Q. A fiber bragg grating pressure sensor and its application to pipeline leakage detection. Advances in Mechanical Engineering 2013; 5: 590451.

[15] Zhang W, Li F, Liu Y. FBG pressure sensor based on the double shell cylinder with temperature compensation. Measurement 2009; 42(3): 408-411.

[16] Zhang WT, Li F, Liu YL, Liu LH. Ultrathin FBG pressure sensor with enhanced responsivity. IEEE Photonics Technology Letters 2007; 19(19): 1553-1555.

[17] Zhang Y, Feng D, Liu Z, Guo Z, Dong X, Chiang KS, Chu BCB. High-sensitivity pressure sensor using a shielded polymer-coated fiber Bragg grating. IEEE Photonics Technology Letters 2001; 13(6): 618-619.

[18] Kanellos GT, Papaioannou G, Tsiokos D, Mitrogiannis C, Nianios G, Pleros N. Two dimensional polymer-embedded quasi-distributed FBG pressure sensor for biomedical applications. Optics Express 2010; 18(1): 179-186.

[19] Zheng S, Zhang X. Simultaneous measurement of pressure and temperature using a single fiber Bragg grating. In: Progress In Electromagnetics Research Symposium 2005, Hangzhou, China, pp. 420-423; 2005. 
[20] Sheng HJ, Fu MY, Chen TC, Liu WF, Bor SS. A lateral pressure sensor using a fiber Bragg grating. IEEE Photonics Technology Letters 2004; 16(4): 1146-1148.

[21] Liu Y, Li L, Zhao L, Wang J, Liu T. Research on a new fiber-optic axial pressure sensor of transformer winding based on fiber Bragg grating. Photonic Sensors 2017; 7(4): 365-371.

[22] Chen X, Zhang D, Wu M. Study of differential fiber Bragg grating seepage pressure sensor. In: American Institute of Physics, Wuhan, China, pp. 060021; 2017.

[23] Song D, Zou J, Wei Z, Yang S, Cui HL. High-sensitivity pressure sensor based on fiber Bragg grating and metal bellows. In: SPIE Defense, Security, and Sensing 2009, Florida, United States, pp. 8; 2009.

[24] Huang J, Zhou Z, Wen X, Zhang D. A diaphragm-type fiber Bragg grating pressure sensor with temperature compensation. Measurement 2013; 46(3): 10411046.

[25] Jiang Q, Du H, Hu D, Yang M. Hydraulic pressure sensor based on fiber Bragg grating. Optical Engineering 2011; 50(6): 064401.

[26] Xiong Y, He J, Yang W, Sheng L, Gao W, Chen Y. Research on FBG pressure sensor of flat diaphragm structure. In: 2012 International Conference on Measurement, Information and Control, Harbin, China, pp. 787-790; 2012.

[27] Díaz CAR, Leal-Junior AG, André PSB, Antunes PFdC, Pontes MJ, Frizera-Neto A, Ribeiro MRN. Liquid level measurement based on FBG-embedded diaphragms with temperature compensation. IEEE Sensors Journal 2018; 18(1): 193-200.

[28] Fu HY, Wu C, Tse MLV, Zhang L, Cheng KCD, Tam HY, Guan BO, Lu C. High pressure sensor based on photonic crystal fiber for downhole application. Applied Optics 2010; 49(14): 2639-2643.

[29] Marques CAF, Peng GD, Webb DJ. Highly sensitive liquid level monitoring system utilizing polymer fiber Bragg gratings. Optics Express 2015; 23(5): 60586072.

[30] Gu YF, Zhao Y, Lv RQ, Yang Y. A practical FBG sensor based on a thin-walled cylinder for hydraulic pressure measurement. IEEE Photonics Technology Letters 2016; 28(22): 2569-2572.

[31] Liu Z, Htein L, Lee KK, Lau KT, Tam HY. Large dynamic range pressure sensor based on two semicircle-holes microstructured fiber. Scientific Reports 2018; 8(1): 65 .

[32] Ahmad H, Harun SW, Chong WY, Zulkifli MZ, Thant MMM, Yusof Z, Poopalan P. High-sensitivity pressure sensor using a polymer-embedded FBG. Microwave and Optical Technology Letters 2008; 50(1): 60-61. 